\title{
PERUMUSAN STRATEGI BISNIS DENGAN PENDEKATAN "GAME THEORY"
}

\author{
Titik Noorida $^{1}$
}

\begin{abstract}
The increase or the Merck and kind of cigarette that revolve in the market had caused a competition in the cigarette tighter. The new Werck that enter the market hardly fight to get the market segment with looking for another Merck's consumer, while the Merc's that had a name in the market for along time must retained to be dead increase their market section or just keep on the market segment that possess it. In the other hand, government always suggests the society not to smoking because of helath reason. This matter, of course little or more influence the growth of cigarette consumption that at the end will make tighter the cigarette product competition the market.

The enterprises that is involved in the competition condition of course will not released from importance of the strategy utilizing optimally so the pproduct that sold will stand survive. The tighten of this competition require the cigarette producer to be creative in looking for the marketing strategy that fit to the product wich risen. One of them is with do the competition analysis. This competition analysis function as to know the speciorities and weakness that is had by main competitors. Beside that enterprise also must be able to catch consumer preference in the aim to consume the cigarette also their perception to the product is risen.

Product grouping is done to know the main competitors Pall Mall product from the product grouping that is done. It's found that Pall Mall tightly compete with Sampoerna A Medium, Wismilak, Diplomat, 234 Filter, and Gudang Garam Internasional Merah Analysis, the competition is made with that main competitor. It so happens the mathod that is used for analyze that competition is Game Theory Method which is used is Two Person Non Zero Sume Game and finished with linear program simplex mathod. The result that is get in this competition analysis is competitions speciorities which is had by product compared with main competitor.

The main purpose from the whole calculation and the data processing is business strategy formulation optimally based on speciorities that is had by product with consider about the speciorities of the main competitor also consumer preference. Formulation will be made specially to the Pall Mall product with the main competitors. The prime thing that is a grip in the business strategy formulation is the speciorities that's had by main competitors and consumer preference to the product attributes.
\end{abstract}

Key Words : Market, Marketing Analysis, Marketing Strategy

\section{PENDAHULUAN}

Semakin banyaknya merk dan jenis rokok yang beredar di pasar telah menyebabkan persaingan dalam pasar rokok makin ketat. Merk-merk baru yang memasuki pasar berjuang keras untuk memperoleh pangsa pasar dengan mencari konsumen baru atau merebut konsumen merk lain, sementara merk-merk yang telah memiliki nama di pasaran harus mati-matian pula meningkatkan pangsa pasarnya atau sekedar mempertahankan pangsa pasar yang dimilikinya. Di lain pihak, pemerintah selalu 
menganjurkan masyarakat untuk tidak merokok karena alasan kesehatan. Hal ini tentunya sedikit banyak akan berpengaruh terhadap pertumbuhan konsumsi rokok yang pada akhirnya akan semakin memperketat persaingan produk rokok di pasaran.

\section{Michael E. Porter} menyebutkan adanya lima faktor yang mempengaruhi kekuatan persaingan industri, yaitu persaingan di antara perusahaan yang ada, ancaman masuknya pendatang baru, ancaman produk-produk pengganti (substitusi), kekuatan tawar menawar pembeli dan kekuatan tawar menawar supplier.

Perusahaan-perusahaan yang terlibat dalam kondisi persaingan tentunya tidak akan terlepas dari kepentingan penggunaan strategi yang optimal agar produk yang dipasarkan tetap survive. Dalam upaya memilih strategi yang optimal dalam memasarkan suatu produk, akan sangat membantu jika keunggulan-keunggulan kompetitif yang dimiliki oleh produk yang bersangkutan dan preferensi konsumen terhadap produk diketahui secara pasti, produsen yang mengetahui secara pasti serta keunggulan-keunggulan kompetitif produk- produk pesaing utamanya serta preferensi konsumen terhadap produk akan lebih mantap dalam mengambil kebijaksanaan strategi bisnisnya. Selama ini keunggulan kompetitif suatu produk kebanyakan dilakukan secara kualitatif berdasarkan hasil survei terhadap pendapat banyak orang, akan tetapi seberapa besar keunggulan tersebut dapat dikeathui secara pasti, dan tentunya cara seperti ini memiliki ketidakpastian yang tinggi. Untuk itu dalam situasi persaingan seperti ini, metode kuantitatif sangat bermanfaat untuk diterapkan walaupun memerlukan banyak waktu, tenaga, pikiran, dan biaya untuk melakukannya. Namun metode kuantitatif akan memberikan hasil yang lebih pasti sehingga pengambilan keputusan strategi bisnis lebih mantap. Metode kuantitatif yang dimaksud, salah satunya adalah teori permainan (Game Teory) untuk menentukan keunggulan-keunggulan kompetitif produk.

\section{LANDASAN TEORI}

\section{Perencanaan Strategi Bisnis}

Proses perencanaan strategi bisnis menurut Philip Kotler adalah sebagai berikut

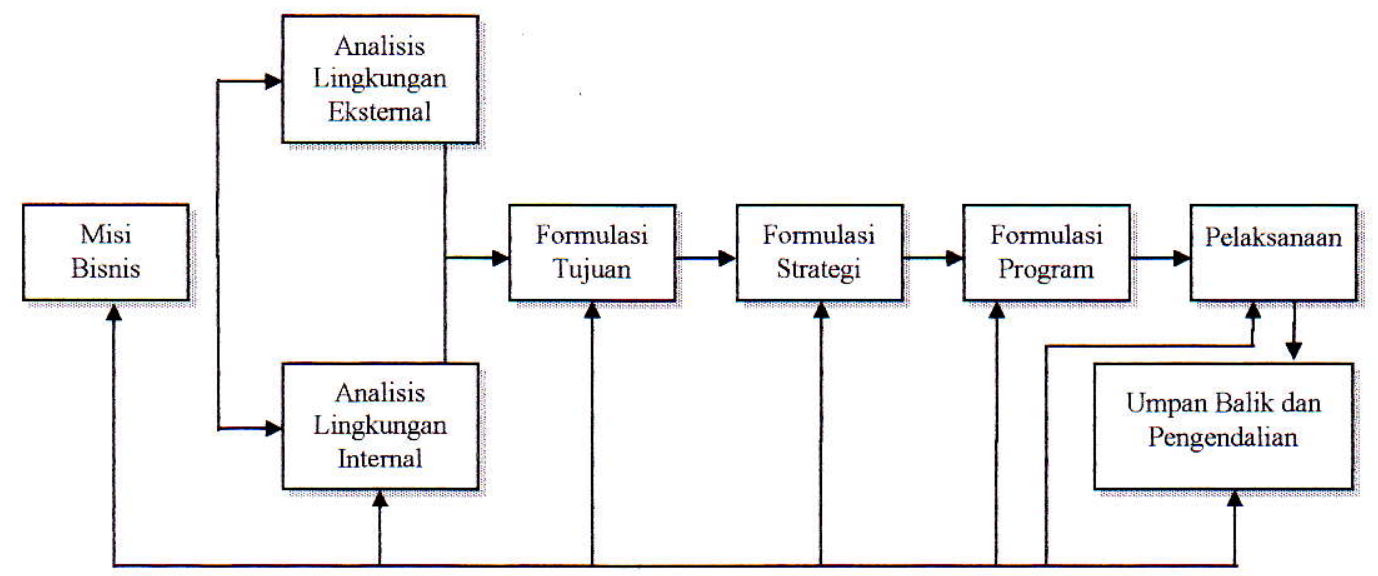




\section{Sistem Pendukung Pemasaran}

Litle [1979] mendefinisikan sistem pendukung pemasaran (marketing decision support system, MDSS) sebagai pengumpulan data, sistem, peralatan dan teknik yang terkoordinasi yang mendukung data, sistem, peralatan dan teknik yang terkoordinasi yang mendukung dimana suatu organisasi mengumpulkan dan menginterpretasi informasi yang relevan dari bisnis dan lingkungan, dan mengubahnya menjadi dasar tindakan pemasaran.

\section{* Peralatan Statistik}

1. Regresi Berganda

2. Analisis Deskriminan

3. Analisis Faktor

4. Analisis Cluster

5. Analisis Conjoint

6. Penyusunan Skala Multi Dimensi

* Permodelan

1. Model Proses Markov

2. Model Antrian

3. Model Prauji Produk Baru

4. Model Tanggapan Penjualan

* Optimasi
1. Kalkulasi Defferensial
2. Pemrograman komputer
3. Teori keputusan Statistik
4. Game Teory
5. Heuristik

\section{Game Theory (Teori Permainan)}

\section{Klasifikasi Game Theory Berdasarkan}

\section{Jumlah Langkah Dan Pilihan}

1. Permainan berhingga (Finite Game), yaitu suatu permainan yang mempunyai sejumlah langkah yang berhingga dengan setiap langkah yang memuat sejumlah pilihan yang berhingga pula.

2. Pemain tak berhingga (Infinite Game), untuk setiap pemain selain pemain berhingga.

\section{Klasifikasi Game Theory Berdasarkan Jumlah Pemain}

1. Pemain 2 orang, jika pihak yang bermain adalah orang. Orang di sini dapat berupa perseorangan atau kelompok.

2. Pemain $\mathrm{n}$ orang, jika pihak yang bermain adalah $n(n>2)$ orang. Orang di sini juga dapat berupa perseorangan atau kelompok.

\section{Klasifikasi Game Theory Berdasarkan} Jumlah Pembayaran

1. Permainan berjumlah nol (Zero Sum Game) adalah suatu permainan dengan jumlah kemenangan kedua belah pihak sama dengan nol. Hal ini berarti bahwa jumlah pembayaran yang diterima bagi salah satu pemain yang menang sama dengan jumlah pembayaran yang dibayarkan oleh pihak yang kalah. Dalam hal ini kemenangan dari pihak yang satu merupakan kekalahan pihak lainnya. Bila ada dua orang yang bermain di dalam permainan, maka dinamakan permainan berjumlah nol dari dua orang (Two Person Zero Sum Game). Dengan demikian apabila di dalam permainan tersebut ada $\mathrm{n}$ orang (pemain) dan jumlah kemenangan mereka sama dengan nol maka dinamakan permainan berjumlah nol 
dari $\mathrm{n}$ orang (n Person, Zero Sum Game). Apabila Pi adalah pembayaran bagi pemain Pi; $\mathrm{I}=1,2,3, \ldots . \mathrm{n}$ dalam permainan itu disebut suatu permainan berjumlah nol.

2. Permainan berjumlah tidak nol (Non Zero Sum Game) yaitu permainan dengan total pembayaran dari masingmasing pemain pada akhir suatu permainan tidak sama dengan nol. Permainan ini dapat dimainkan oleh dua orang ataupun $\mathrm{n}$ orang. Bila ada dua orang bermain dalam permainan, maka dinamakan permainan berjumlah bukan nol dari dua orang (Two Person Non Zero Sum Game).

\section{Pay Off Matriks (Matriks Pembayaran)}

1. Pay off matrik untuk permainan berjumlah nol dari dua orang (two person zero sum game)

2. Pay off matrik untuk permainan berjumlah nol dari $\mathrm{n}$ orang ( $\mathrm{n}$ person zero sum game)

3. Pay off matrik untuk permainan berjumlah bukan nol dari doa orang (two person non zero sum game)
4. Pay off matrik untuk permainan berjumlah bukan nol dari $\mathrm{n}$ orang $(n$ person non zero sum game)

Pay Off Matrik (Matrik Pembayaran) untuk Pemain Berjumlah Nol dari Dua Orang (Zero Sum Game)

\begin{tabular}{|c|c|c|c|c|c|}
\hline & & \multicolumn{5}{|c|}{ Pemain Kedua (P2) } \\
\hline Pernain & & Yl & Y2 & Y3 & \\
\hline Pertama & $\mathrm{Xl}$ & $\mathrm{a} 11$ & $\mathrm{a} 12$ & $\mathrm{a} 13$ & $\mathrm{a} 1 \mathrm{n}$ \\
\hline & $\mathrm{X} 2$ & $\mathrm{a} 21$ & $\mathrm{a} 22$ & $\mathrm{a} 23$ & $\mathrm{a} 2 \mathrm{n}$ \\
\hline & $\mathrm{X} 3$ & $\cdot$ & & & \\
\hline & $\cdot$ & $\cdot$ & & & \\
\hline & $\cdot$ & $\cdot$ & & & \\
\hline & $\mathrm{Xm}$ & $\mathrm{am} 1$ & $\mathrm{am} 2$ & $\mathrm{am} 3$ & $\mathrm{amm}$ \\
\hline
\end{tabular}

Keterangan :

$>\mathrm{M}$ adalah banyaknya srategi yang dipunyai pemain $\mathrm{Pl}$

$>\mathrm{N}$ adalah banyaknya strategi yang dipunyai pemain $\mathrm{P} 2$

$>\operatorname{Aij} ; \mathrm{I}=1,2 \ldots \ldots \ldots \ldots \mathrm{m}$ dan $\mathrm{j}=1,2$, adalah nilai pembayaran (yang didefinisikan secara numerik = bilangan positif, bilangan negatif atau nol) yang bersesuaian dengan strategi ke-I bagi pemain P1 dan strategi ke-j bagi pemain P2

Pay Off Matrik (Matrik Pembayaran) untuk Pemain Berjumlah Tidak Nol dari Dua Orang (Non Zero Sum Game)

\begin{tabular}{|c|c|c|c|c|c|}
\hline & J & \multicolumn{4}{|c|}{ Pemain Kedua (P2) } \\
\hline & $\mathrm{I}$ & 1 & 2 & 3 & $\ldots \ldots . . \mathrm{n}$ \\
\hline Pemain & 1 & $(\mathrm{a} 11, \mathrm{~b} 11)$ & $(\mathrm{a} 12, \mathrm{~b} 12)$ & $(\mathrm{a} 13, \mathrm{~b} 13)$ & $\ldots(\mathrm{a} \ln , \mathrm{b} 1 \mathrm{n})$ \\
\hline Pertama & 2 & $(\mathrm{a} 21, \mathrm{~b} 21)$ & $(\mathrm{a} 22, \mathrm{~b} 22)$ & $(\mathrm{a} 23, \mathrm{~b} 23)$ & $\ldots(\mathrm{a} 2 \mathrm{n}, \mathrm{b} 2 \mathrm{n})$ \\
\hline (P1) & 3 &. & & & \\
\hline &. &. & & & \\
\hline & $\mathrm{m}$ & $(\mathrm{am} 1, \mathrm{bm} 1)$ & $(\mathrm{am} 2, \mathrm{bm} 2)$ & $(\mathrm{am} 3, \mathrm{bm} 3)$ & $\ldots$ (amn, bmn) \\
\hline
\end{tabular}

\section{Keterangan :}

> M adalah banyaknya srategi yang dipenuhi pemain $\mathrm{P} 1$
$\mathrm{N}$ adalah banyaknya strategi yang dipenuhi pemain P2 
Aij ; I = 1, $2 \ldots \ldots . m$ dan $\mathrm{j}=1,2, \ldots \ldots . \mathrm{n}$ adalah nilai pembayaran untuk pemain P1

$>\operatorname{Bij} ; \mathrm{I}=1,2 \ldots \ldots \mathrm{m}$ dan $\mathrm{j}=1,2, \ldots \ldots \mathrm{n}$ adalah nilai pembayaran untuk pemain P2 yang bersesuaian dengan strategi ke1 bagi pemain P1 dan strategi ke-j bagi pemain $\mathbf{P} 2$.

\section{Analisis :}

\section{Penyelesaian Game Theory dengan}

\section{Metode Aljabar}

Suatu permainan berjumlah nol dari dua orang dengan masing-masing pemain mempunyai dua pilihan strategi (langkah) dapat diselesaikan dengan metode aljabar. Prinsip penggunaan metode aljabar untuk menyelesaikan permainan ini adalah bahwa kedua pemain P1 dan P2 membagi waktu (sesuai proporsinya) yang diperlukan untuk memilih suatu strategi.

\section{Penyelesaian Game Theory dengan Metode Grafik}

Metode grafik hanya dapat digunakan untuk menyelesaikan suatu permainan bila dalam permainan ini di dapat paling sedikit seorang pemain yang hanya mempunyai dua pilihan strategi sehingga permainan yang dapat diselesaikan dengan metode grafik ini berukuran $2 \times 2,2 \times \mathrm{n}$ atau $\mathrm{m} \times 2$, di dalam menyelesaikan permainan yang hanya mempunyai dua strategi tersebut didapatkan barulah kemudian menghitung strategi. Hal tersebut dapat dilakukan dengan menghitungnya dengan menggunakan aturan dualitas program linier

\section{Uji Kecukupan Data}

Jumlah sampel minimum yang diperlukan dalam penelitian ini menurut Bernaulli dapat kita tentukan dengan rumus sebagai berikut :

$$
\mathrm{N}=\frac{\left(\frac{\mathrm{z} \cdot \alpha}{2}\right)^{2} \mathrm{p} \cdot \mathrm{q}}{\mathrm{e}^{2}}
$$

dimana :

$\mathrm{N}$ : jumlah sampel minimum

$\alpha$ : $\quad$ taraf keberartian $(0,05)$

$\mathrm{z} \quad$ : nilai distribusi normal

e : tingkat kesalahan

$\mathrm{p}$ : proporsi konsumen yang menggunakan

q : proporsi konsumen yang tidak menggunakan

\section{Uji Validitas dan Reabilitas}

\section{* Uji Validitas}

Uji Validitas digunakan sebagai ukuran seberapa akurat suatu alat tes melakukan fungsi ukurannya. Apabila Validitas yang didapat semakin tinggi, maka tes tersebut semakin mengenai sasarannya.

$$
r=\frac{N(\Sigma X Y)-\left(\sum X \cdot \Sigma Y\right)}{\left[N \Sigma X^{2}-(\Sigma X)^{2}\left[N \Sigma Y^{2}-(\Sigma Y)^{2}\right]^{1 / 2}\right.}
$$

Dimana :

$$
\begin{array}{cll}
\mathrm{X} & : & \text { skor tiap-tiap variabel } \\
\mathrm{Y} & : & \text { skor total tiap responden } \\
\mathrm{N} & : & \text { jumlah responden }
\end{array}
$$

\section{* Uji Reabilitas}

Digunakan untuk menguji keajegan/kekonsistenan hasil pengukuran angket yang erat 
hubungannya dengan masalah kepercayaan.

Rumus korelasi Alpha Cronbach

$$
\mathrm{Rtt}=\frac{\mathrm{M}}{\mathrm{M}-1}-\frac{\mathrm{Vt}-\mathrm{Vx}}{\mathrm{Vt}}
$$

Dimana :

Vt : variasi total

$\mathrm{Vx}$ : variasi butir-butir

M : jumlah butir

Rtt $>0,04$

\section{METODOLOGI PENELITIAN}

Data yang diperlukan dalam penelitian ini adalah antara lain data primer dan kunder yang masing-masing dapat dijabarkan sebagai berikut:

1. Merek rokok yang beredar dipasar,

2. Merek rokok yang dikenal,

3. Merek-merek rokok yang banyak dikonsumsi,

4. Atribut-atribut yang dipertimbangkan oleh kondumen,

5. Atribut-atribut yang dipertimbangkan oleh sebagian besar konsumen

\section{HASIL DAN PEMBAHASAN}

\section{Analisa Permainan Gudang Garam \\ Internasional Merah - Pall Mall}

Pada permainan GGIM - Pall Mall, hasil yang diperoleh dari penyelesaian persamaan linier adalah sebagai berikut :

* Pemain P1 (GGIM)

- Nilai fungsi obyektif yang didapat adalah sebesar 0,34648
- Nilai variabel yang didapatkan oleh GGIM adalah :

$$
\begin{aligned}
& \mathrm{X} 1=0,34473 \\
& \mathrm{X} 9=0,00175
\end{aligned}
$$

\section{* Pemain P2 (Pall Mall)}

- Nilai fungsi obyektif yang didapat adalah sebesar 0,2037

- Nilai variabel yang didapatkan oleh GGIM adalah :

$$
\begin{aligned}
& \mathrm{X} 10=0,03854 \\
& \mathrm{X} 11=0,15498 \\
& \mathrm{X} 12=0,01209
\end{aligned}
$$

\section{Analisa Permainan Djie Sam Soe Filter -}

\section{Pall Mall}

Pada permainan 234 Filter - Pall Mall, hasil yang diperoleh dari penyelesaian persamaan linier adalah sebagai berikut :

- Pemain P1 (234 Filter)

- Nilai fungsi obyektif yang didapat adalah sebesar 0,3773

- Nilai variabel yang didapatkan oleh 234 Filter adalah :

$$
\begin{aligned}
& X 1=0,3696 \\
& X 5=0,0077
\end{aligned}
$$

Pemain P2 (Pall Mall)

- Nilai fungsi obyektif yang didapat adalah sebesar 0,2037

- Nilai variabel yang didapatkan oleh 234 Filter adalah :

$$
\begin{aligned}
& \mathrm{X} 10=0,03854 \\
& \mathrm{X} 11=0,15498 \\
& \mathrm{X} 12=0,01209
\end{aligned}
$$




\section{Analisa Permainan Wismilak Diplomat -} Pall Mall

Pada permainan Wismilak Diplomat - Pall Mall, hasil yang diperoleh dari penyelesaian persamaan linier adalah sebagai berikut :

* Pemain P1 (Wismilak Diplomat)

- Nilai fungsi obyektif yang didapat adalah sebesar 0,33121

- Nilai variabel yang didapatkan oleh Wismilak Diplomat adalah :

$$
\begin{aligned}
& \mathrm{X} 1=0,3079 \\
& \mathrm{X} 5=0,0233
\end{aligned}
$$

* Pemain P2 (Pall Mall)

- Nilai fungsi obyektif yang didapat adalah sebesar 0,2037

- Nilai variabel yang didapatkan oleh GGIM adalah :

$$
\begin{aligned}
& \mathrm{X} 10=0,03854 \\
& \mathrm{X} 11=0,15498 \\
& \mathrm{X} 12=0,01209
\end{aligned}
$$

\section{Analisa Permainan Sampoerna A \\ Medium - Pall Mall \\ Pada permainan Sampoerna A} Medium - Pall Mall, hasil yang diperoleh dari penyelesaian persamaan linier adalah sebagai berikut :

\section{* Pemain P1 (Sampoerna A Medium)}

- Nilai fungsi obyektif yang didapat adalah sebesar 0,2018

- Nilai variabel yang didapatkan oleh Sampoerna A Medium adalah :

$$
\begin{array}{ll}
\mathrm{X} 7 & =0,020387 \\
\mathrm{X} 8 & =0,00314 \\
\mathrm{X} 10 & =0,0691 \\
\mathrm{X} 11 & =0,07632 \\
\mathrm{X} 12 & =0,03285
\end{array}
$$

* Pemain P2 (Pall Mall)

- Nilai fungsi obyektif yang didapat adalah sebesar 0,35088

- Nilai variabel yang didapatkan oleh GGIM adalah :

$\mathrm{X} 1=0,35088$

\section{Analisa Keunggulan dan Kelemahan Kompetitif Produk Pall Mall}

Dari keseluruhan perhitungan nilai permainan yang telah dilakukan, hasil yang diperoleh adalah sebagai berikut :

Pada permainan antara GGIM - Pall Mall nilai security level yang didapatkan oleh GGIM adalah 2,8862 yang didukung oleh keunggulan kompetitif atribut-atribut : Kemantapan Rasa sebesar $99,49 \%$ dan Kekonsistenan Rasa sebesar 0,51\%. Sedangkan nilai security yang didapatkan Pall Mall adalah 4,8638 yang didukung oleh atribut-atribut Image Perusahaan sebesar 18,75\%, Kemasan Produk sebesar $75,38 \%$ dan Keekonomisan harga sebesar $5,88 \%$. Berdasarkan hasil tersebut dapat disimpulkan bahwa dalam persaingan antara GGIM dan Pall Mall, GGIM unggul dalam hal kemantapan rasa dan kekonsistenan rasa. Sedangkan Pall Mall unggul dalam hal image perusahaan, kemasan produk dan keekonomisan harga. Dalam suatu persaingan, keunggulan yang tidak dimiliki oleh suatu produk tetapi dimiliki oleh produk lain berarti merupakan kelemahan produk yang 
bersangkutan. Hal ini berarti bahwa dalam persaingan antara GGIM dengan Pall Mall, GGIM lemah dalam hal image perusahaan, kemasan produk dan kekonsistenan harga. Sebaliknya Pall Mall lemah dalam hal kemantapan rasa dan kekonsistenan rasa.

* Pada permainan antara 234 Filter - Pall Mall. Nilai security yang didapatkan oleh 234 Filter sebesar 2,6504 yang didukung oleh keunggulan kompetitif atribut-atribut : Kemantapan Rasa sebesar 97,96\% dan Keawetan Aroma sebesar 2,04\%. Sedangkan nilai security yang didapatkan Pall Mall adalah 4,8638 yang didukung oleh atributatribut : Image Perusahaan sebesar $18,75 \%$, Kemasan Produk sebesar $75,38 \%$ dan Keekonomisan Harga sebesar 5,88\%. Berdasarkan hasil tersebut dapat disimpulkan bahwa dalam persaingan antara 234 Filter dengan Pall Mall, 234 Filter unggul dalam hal kemantapan rasa dan keawetan aroma, namun lemah dalam hal image perusahaan, kemasan produk dan keekonomisan harga.

* Pada permainan antara Wismilak Diplomat - Pall Mall, nilai security level yang didapatkan oleh Wismilak Diplomat adalah 3,0192 yang didukung oleh keunggulan kompetitif atributatribut : Kemantapan Rasa sebesar 92,96\% dan Keawetan Aroma sebesar $7,03 \%$. Sedangkan nilai security level yang didapatkan oleh Pall Mall sebesar 4,8638 yang didukung oleh keunggulan kompetitif atribut-atribut : Image Perusahaan sebesar 18,75\%, Kemasan Produk sebesar $75,38 \%$ dan Keekonomisan Harga sebesar 5,88\%. Berdasarkan hasil tersebut dapat disimpulkan bahwa dalam persaingan antara Wismilak Diplomat dengan Pall Mall, Wismilak Diplomat unggul dalam hal kemantapan rasa dan keawetan aroma, namun lemah dalam hal image perusahaan, kemasan produk dan keekonomisan harga.

* Pada permainan antara Sampoerna A Medium - Pall Mall, nilai security level yang didapatkan oleh Pall Mall sebesar 2,8499 yang didukung oleh keunggulan kompetitif atribut-atribut : Kemantapan Rasa sebesar 100\%. Desangkan nilai security yang didapatkan oleh Sampoerna A Medium sebesar 4,9554 yang didukung oleh keunggulan kompetitif atribut-atribut : Kadar Tar dan Nikotin sebesar 10,1\%, Gengsi/prestise sebesar 1,56\%, Image Perusahaan sebesar $34,24 \%$, Kemasan Produk sebesar $37,82 \%$ dan Keekonomisan Harga sebesar 16,28\%. Berdasarkan hasil tersebut, maka dapat disimpulkan bahwa dalam persaingan antara Pall Mall dengan Sampoerna A Medium, Pall Mall unggul dalam hal kemantapan rasa, namun lemah dalam hal kadar tar dan nikotin, gengsi/prestise, image perusahaan, kemasan produk, dan keekonomisan harga. 


\section{KESIMPULAN}

1. Dari hasil analisis faktor dan analisis cluster didapatkan pengelompokan merek rokok berdasarkan persepsi konsumen yang bersaing secara ketat, diantaranya adalah :

* Lucky Strike, Marlboro Merah

* Sampoerna A Medium, Pall Mall, Wismilak Diplomat, 234 Filter, Gudang Garam Internasional Merah

\section{* Gudang Garam Surya 12}

* Bentoel Internasional, Djarum Super 12

2. Dari keseluruhan perhitungan nilai security level didapatkan hasil analisa keunggulan persaingan masing-masing produk, diantaranya adalah :

* Pada permainan antara GGIM Pall Mall

GGIM memiliki keunggulan kompetitif atribut-atribut kemantapan rasa dan kekonsistenan rasa. Sedangkan Pall Mall memiliki keunggulan kompetitif atributatribut : image perusahaan, kemasan produk, dan keekonomisan harga.

* Pada permainan antara 234 Filter Pall Mall

234 Filter memiliki keunggulan kompetitif atribut-atribut kemantapan rasa dan keawetan aroma. Sedangkan Pall Mall memiliki keunggulan kompetitif atribut-atribut : image perusahaan, kemasan produk, dan keekonomisan harga.

* Pada permainan antara Wismilak Diplomat - Pall Mall

Wismilak Diplomat memiliki keunggulan kompetitif atributatribut kemantapan rasa dan kekonsistenan rasa. Sedangkan Pall Mall memiliki keunggulan kompetitif atribut-atribut : image perusahaan, kemasan produk, dan keekonomisan harga.

* Pada permainan antara Sampoerna A Medium - Pall Mall

Pall Mall memiliki keunggulan kompetitif atribut-atribut kemantapan rasa. Sedangkan Sampoerna A Medium memiliki keunggulan kompetitif atributatribut : kadar tar dan nikotin, gengsi/prestise, image perusahaan, kemasan produk, dan keekonomisan harga.

3. Perumusan strategi bisnis yang sesuai bagi PT. Rothmans Of Pall Mall untuk memasarkan produk-produknya khususnya rokok Pall Mall adalah dengan mempertahankan image yang saat ini tergolong baik di mata konsumen, memposisikan produk rokok Pall Mall berdasarkan keunggulan kompetitif yang dimilikinya sesuai dengan lawannya, dan memperbaiki kelemahan-kelemahan atribut produk yang didapat dari persepsi dan preferensi konsumen. 


\section{DAFTAR PUSTAKA}

Aacker, Kumar, Das. 1995. Marketing Research, Edisi Kelima, John Wiley \& Sons Inc, Canada,

Billy E, Gillet, 1982. Introduction To Operation Research A Computer Orianted Algorithmic Approach. Magraw-Hill, Inc. New York,

Kotler, Philip, 1995. Manajemen Pemasaran : Analisis, Perencanaan, Implementasi dan Pengendalian, Jilid Satu, Edisi Kedelapan (Terjemahan), Salemba Empat, Jakarta,

Kertajaya, Hermawan, 1997.. Marketing Plus 2000 Siasat Memenangkan Persaingan Global. Edisi Pertama,
PT. Gramedia Pustaka Utama, Jakarta,

Mushali Anshori, 1999. Jurnal Pengaruh Kemampuan Pemasaran dan Strategi Bisnis Terhadap Kinerja Bisnis Pada Perusahaan Manufaktur di Indonesia, Universitas Airlangga,

Porter, Michael E, agus Maulana, 1989. Strategi Bersaing : Teknik Menganalisis Industri dan Pesaing, Edisi Kedua (Terjemahan), Erlangga,

Singgih Santoso, Fandy Tjiptono, 2001. Riset Pemasaran : Konsep dan Aplikasi Dengan SPSS Versi 10, Edisi Pertama, PT. Gramedia, Jakarta 